\title{
Effect of Experience Facilitating Problem-Based Learning (PBL) on Physician Assistant Student Outcomes
}

\author{
Susan Hawkins \\ Chatham University, hawkins@chatham.edu \\ Anthony Goreczny \\ Chatham University, goreczny@chatham.edu \\ Nicole E. Brown \\ Chatham University, nbrown1@chatham.edu
}

Follow this and additional works at: https://nsuworks.nova.edu/ijahsp

Part of the Medicine and Health Sciences Commons, and the Scholarship of Teaching and Learning Commons

\section{Recommended Citation}

Hawkins S, Goreczny A, Brown NE. Effect of Experience Facilitating Problem-Based Learning (PBL) on Physician Assistant Student Outcomes. The Internet Journal of Allied Health Sciences and Practice. 2018 Jan 01;16(3), Article 5.

This Manuscript is brought to you for free and open access by the College of Health Care Sciences at NSUWorks. It has been accepted for inclusion in Internet Journal of Allied Health Sciences and Practice by an authorized editor of NSUWorks. For more information, please contact nsuworks@nova.edu. 


\title{
Effect of Experience Facilitating Problem-Based Learning (PBL) on Physician Assistant Student Outcomes
}

\begin{abstract}
Abstract

Purpose: The impact of prior problem-based learning (PBL) facilitation experience (measured by length of time facilitating) on student learning and student outcomes is unclear. The purpose of this study was to evaluate relationships of facilitator experience in problem-based learning on student outcomes. This study utilized both modified essay questions (MEQ) in the form of patient management assessments and multiple choice question (MCQ) assessments to evaluate different aspects of student acquisition and application of knowledge. Method: This study examined scores from six multiple choice question examinations and six patient management assessments (PMA), one each from six 5-week units arranged by organ system administered to five cohorts of first-year physician assistant students in a hybrid problembased learning program where 18 of 45 didactic credits are solely problem-based learning. Facilitation experience, measured in total number of prior units facilitated, was calculated for each facilitator and compared with student evaluative measures. Results: Pearson product moment correlations comparing facilitator experience and scores on the patient management assessments and multiple choice question tests showed no statistically significant correlations between facilitator experience and student outcomes. Univariate analysis of variance tests comparing whether faculty were full-time versus adjunct status and status as graduates of a problem-based learning program versus graduates of programs with other pedagogies with student outcomes showed no statistically significant differences. Conclusions: Neither experience of the facilitator, nor status as full-time versus adjunct, nor status as graduate of a problembased learning program versus other pedagogy was related to student outcomes. Each facilitator in the study participated in training, observation, and weekly meetings, which may outweigh the effects of facilitator experience. Other factors in need of exploration related to student outcomes in future studies include individual intellectual ability, emotional stability, motivation, self-efficacy, and perseverance.
\end{abstract}

\section{Author Bio(s)}

Susan Hawkins, MSEd, PA-C, is an associate professor and Problem-based Learning (PBL) Coordinator in the Physician Assistant Studies program at Chatham University in Pittsburgh, PA. She also does PBL trainings for faculty nationwide and serves as an ARC-PA accreditation site visitor.

Nicole Brown, MS, PA-C, is an assistant professor and Skills Coordinator in the Physician Assistant Studies program at Chatham University in Pittsburgh, PA. She also practices clinically in emergency medicine at Magee-Womens Hospital of UPMC.

Anthony J. Goreczny, PhD, is a professor in the Counseling Psychology program at Chatham University in Pittsburgh, PA,. He maintains a private practice with interests in the areas of Developmental Disabilities, Health Psychology, Assessment, Clinical and Educational Psychology, and Ethical, Legal and Psychological Implications of Genetics Technologies. 


\title{
TIUASP' \\ The Internet Joư⿱n一⿰口乚一al of Allied Health Sciences and Practice
}

Dedicated to allied health professional practice and education

Vol. 16 No. 3 ISSN 1540-580X

\section{Effect of Experience Facilitating Problem-Based Learning (PBL) on Physician Assistant Student Outcomes}

\author{
Susan Hawkins, MSEd., PA-C \\ Anthony Goreczny, Ph.D. \\ Nicole E. Brown, MS, PA-C \\ Chatham University \\ United States
}

\begin{abstract}
Purpose: The impact of prior problem-based learning (PBL) facilitation experience (measured by length of time facilitating) on student learning and student outcomes is unclear. The purpose of this study was to evaluate relationships of facilitator experience in problem-based learning on student outcomes. This study utilized both modified essay questions (MEQ) in the form of patient management assessments and multiple choice question (MCQ) assessments to evaluate different aspects of student acquisition and application of knowledge. Method: This study examined scores from six multiple choice question examinations and six patient management assessments (PMA), one each from six 5-week units arranged by organ system administered to five cohorts of first-year physician assistant students in a hybrid problem-based learning program where 18 of 45 didactic credits are solely problem-based learning. Facilitation experience, measured in total number of prior units facilitated, was calculated for each facilitator and compared with student evaluative measures. Results: Pearson product moment correlations comparing facilitator experience and scores on the patient management assessments and multiple choice question tests showed no statistically significant correlations between facilitator experience and student outcomes. Univariate analysis of variance tests comparing whether faculty were full-time versus adjunct status and status as graduates of a problem-based learning program versus graduates of program with other pedagogies with student outcomes showed no statistically significant differences. Conclusions: Neither experience of the facilitator, nor status as full-time versus adjunct, nor status as graduate of a problem-based learning program versus other pedagogy was related to student outcomes. Each facilitator in the study participated in training, observation, and weekly meetings, which may outweigh the effects of facilitator experience. Other factors in need of exploration related to student outcomes in future studies include individual intellectual ability, emotional stability, motivation, self-efficacy, and perseverance.
\end{abstract}

Key Words: problem-based learning, case-based learning, facilitation, assessment 


\section{INTRODUCTION}

Problem-based learning (PBL) has an ever-growing presence in academic programs internationally, both at the undergraduate and graduate level. ${ }^{1}$ Students are assigned to small groups and tasked to work through a complex problem, typically a patient scenario in medical curricula. In the initial session, referred to as the pre-discussion phase, students become familiar with the problem and utilize prior knowledge to create a list of possible solutions (ie, differential diagnoses). ${ }^{2}$ As students progress through the problem, they discuss conflicts in prior knowledge and determine what topics are unclear and require further investigation (referred to as learning issues). ${ }^{2}$ Responsibility to research and understand learning issues prior to the next session is placed on students, thereby encouraging them to develop self-directed learning skills and become life-long learners. ${ }^{1,3-6}$ This phase is aptly named the self-study phase. ${ }^{2}$ In the reporting phase, which occurs during the next session, students apply information obtained from learning issues to the problem, thus promoting a deep understanding of material via knowledge integration and conceptual change.1,2, This "constructivist" nature of PBL also promotes development of effective communication and collaborative team skills that ultimately help students to be world-ready. $1,4,5,7$

In addition, PBL has consistently been found to be more effective for long-term retention of knowledge, as compared to lectures, due to the high level of engagement required. 2,4,6 Students report increased interest and attention during PBL sessions as well as increased confidence. ${ }^{1,8}$ Prosser and Sze reviewed multiple meta-analyses comparing PBL to lecture courses and found that PBL leads to better long-term retention of knowledge and focuses more on clinical reasoning skills compared to lectures; however, lectures are better than PBL for short-term retention of information. ${ }^{4}$ Interestingly, Prosser and Sze also found that students who have a thorough understanding of PBL philosophy will frequently explore and apply concepts, thus being more likely to benefit from PBL than those students who do not understand the philosophy. ${ }^{4}$

\section{Experience of PBL Facilitator}

The role of the facilitator in PBL, also referred to as tutor, has been an ongoing area of interest in research due to the important role the facilitator plays in this pedagogy. PBL facilitators ask probing questions throughout sessions but do not give information as to whether information relayed by students is accurate. ${ }^{4}$ The facilitator directly affects group functioning, and as such, specific attributes of successful facilitators is an area of interest for many programs who have either implemented or plan to implement PBL into their curricula. 8,9 Although there are multiple models and viewpoints of PBL pedagogy, many educators agree that facilitators help to guide students through cases and the process of PBL, particularly when students are unfamiliar with this process. ${ }^{10}$ Facilitators are expected to be generally knowledgeable about content of material being covered, know if and when to provide guidance via questioning, aid in refining learning issues, encourage group discussions, promote application of knowledge gained, and provide feedback. $3,5,7,8,11$

Impact of the number of years that a faculty member has used PBL pedagogy on student learning and student outcomes is unclear. There has been much debate on what constitutes facilitator experience in PBL as studies within the literature define expertise in various ways. Some studies define experts as those with prior facilitation experience (for example, by number of years of facilitating, presence/absence of facilitation experience, or defined minimum number of terms of facilitation experience), though most studies focus on presence or absence of content (subject- matter) expertise. ${ }^{8}$ In addition, there are variations in how a content expert is defined, further complicating the literature. For example, in a study performed by Park et al11, content experts in a dental school course were those who were prosthodontic specialists and non-experts were general dentists whereas another study by Bochner et al ${ }^{9}$ assigned expertise "classifications" based on three categories: highest educational degree obtained, familiarity with subject content, and prior PBL facilitator experience. A third example, a study by Gingerich et al ${ }^{12}$, divided experience of facilitators in a medical school program into those who were Doctors of Medicine (M.D.), those who were Doctors of Philosophy (Ph.D.), and all other health professionals (including chiropractors, a dentist, a naturopathic doctor, a pharmacist, and a physiotherapist). In contrast, a meta-analysis by Leary et al13 defined content non-experts (also called novices) as those with the same educational degree as the student; thus, both students and facilitator may be considered novices if their educational degree is the same. Numerous approaches to defining what constitutes a content expert obscure the ability to directly compare studies utilizing different definitions of expertise.

There is a paucity of primary research within the literature focusing on facilitator experience in PBL in relation to student outcomes; research examined did not find a consistent effect of number of years that a faculty member used PBL pedagogy on student outcomes. ${ }^{13,14}$ Park et al11 categorized PBL facilitators as experienced if they had facilitated at least one year in a dental school course; student outcomes evaluated included: grades for tutorial session, laboratory scores, midterm and final examinations, and overall course grades. Park et al ${ }^{11}$ also accounted for content expertise, where prosthodontic specialists were content experts and non-experts were general dentists. In this case, there was no difference in overall grade between experienced and non-experienced facilitators with the exception of the final examinations where students had higher scores

(c) The Internet Journal of Allied Health Sciences and Practice, 2018 
when facilitated by content experts without experience. The authors concluded that student performance was not affected by the level of facilitator experience outside of final examinations. ${ }^{11}$

Another study performed by Hawkins et al ${ }^{14}$ compared novice and experienced PBL facilitators in terms of student outcomes on multiple-choice examinations (MCQ) and written scenario-based patient management problem (PMP) examinations. Hawkins et al14 found that there was a significant difference in a student's $M C Q$ score for a particular unit depending on a student's facilitator when compared to that same student's overall average MCQ score for the year, though this was not true of the PMP. In addition, Hawkins et al ${ }^{14}$ found that students scored more favorably on both the MCQ and the PMP when facilitated by an experienced PBL facilitator (7-10 years of experience) compared to a novice facilitator (less than 1 year of experience). Hawkins et al ${ }^{14}$ also found that experienced facilitators affected student rankings on both the MCQ and the PMP, meaning that those with experienced facilitators ranked higher on their examinations than those with novice facilitators. Finally, it was noted that novice facilitators had a higher number of poorly performing students on MCQ examinations compared to experienced facilitators. Based on these results, it was concluded that the number of years a faculty member used PBL pedagogy may affect student outcomes on the above PA program evaluative measures. ${ }^{14}$

In the first meta-analysis focusing on PBL facilitator background and training, Leary et al13 analyzed 144 outcomes in terms of facilitator experience and its effects on student outcomes. Leary et al ${ }^{13}$ noted a "modest negative relationship" where more experienced facilitators had worse student outcomes in terms of test scores and student learning; this was only noted when PBL was utilized in more than one class within the curriculum. In programs where PBL was utilized in only one class, there was no significant relationship found between PBL experience level and student outcomes. It is important to note that Leary et al13 suggested the analysis was limited as many studies were excluded due to vague descriptions of facilitator experience (ie, presence/absence of experience) instead of quantitative definitions of experience.

\section{Multiple Choice Examination Questions versus Modified Essay Questions for Assessment}

In terms of assessing knowledge gained through the didactic portion of medical curricula, there are numerous options, but these typically either fall into open-ended or closed-ended type questions. ${ }^{15,16}$ Closed-ended questions refer to questions where the definite answer is given, with examples including true/false, multiple-choice, and extended matching item (EMI) questions. ${ }^{16}$ Open-ended questions, however, encompass those where each student is required to compile an answer based on his/her prior knowledge base. Examples include short answer questions (SAQ), essays, and modified essay questions (MEQs). ${ }^{16}$ Because reliability and validity of MCQs are simple to determine and can encompass a wide variety of content on one examination, they are ubiquitous in higher education. ${ }^{15,16}$ In addition, MCQs are cost-effective and easiest to grade because availability of computer-based testing has increased. ${ }^{15}$ Some researchers suggest that properly written MCQ questions evaluate levels of thinking similar to short answer or essay questions but are very difficult to write. $15-17$ "Cueing" occurs frequently with MCQs, meaning that students are able to identify the correct answer because it is an option given. ${ }^{15,17}$ This can thus lead to increased MCQ test scores when compared to other testing formats such as short answer or MEQs. ${ }^{17}$ One way to avoid cueing and assess complex thinking patterns is with open-ended or short answer questions because these allow students to formulate their own answers based on previously acquired knowledge. Modified essay questions (MEQs) assess multiple aspects of the same content by requiring each student to solve a problem that is separated into parts, each requiring somewhat different knowledge, thus combining characteristics of both MCQs and essays. ${ }^{17}$ Other terms for this type of testing in medical curricula include "patient management problem" or "patient management assessments." As each student progresses through the problem, that student critically assesses the scenario and answers the associated question(s). After each step, that student is given additional information to help progress through each page of the examination. ${ }^{17}$

There are several limitations noted in the literature regarding use of MEQs. First, these types of assessments are more difficult to grade than are MCQs given the wide variety of student responses and are significantly more time-consuming to grade. ${ }^{15}$ Very specific criteria are needed for MEQs to ensure fairness of grading due to poor inter-rater reliability in grading these assessments. ${ }^{15,16}$ In addition, attempts to improve reliability have tended to lead to a decrease in ability to test higher level cognitive thinking. ${ }^{16}$ It has previously been suggested that MEQs test a different aspect of critical thinking than MCQs; however, in a study by Palmer and Devitt who evaluated use of MCQs and MEQs in a summative course assessment, it was found that the majority of MEQs in their study evaluated only factual recall from students. ${ }^{17}$ In addition, this study also found that MCQs were better at evaluating higher levels of critical thinking than the MEQs that were administered. The researchers speculated that this was due to composition of the MCQ and MEQ questions. ${ }^{17}$ However, in a review by Hift, a high correlation between MCQ and open-ended questions was noted to be present when the questions focused on the same material and assessed the same level of cognition, implying that these questions assessed the same construct. ${ }^{16}$ Therefore, construction of MEQ questions is crucial to ensure that they are testing clinical reasoning skills and not simply factual recall, assuming that assessing higher level thinking is the intended purpose. ${ }^{17}$

(c) The Internet Journal of Allied Health Sciences and Practice, 2018 


\section{Purpose of the Study}

Overall, the literature has not clearly defined expert versus novice facilitators in terms of PBL experience level, and this inconsistency impedes the ability to make generalizations based on currently available scientific studies. ${ }^{8,9}$ Hawkins et al ${ }^{14}$ dichotomized facilitators into experienced and novice groups, thereby obscuring identification of other possible relationships. The current study utilized the full range of facilitator experience and used a larger number of facilitators and a larger number of subjects compared to the previous study. Furthermore, some prior studies assessed student outcomes in terms of examination scores whereas others evaluated student perception of PBL effectiveness in learning. ${ }^{7-8}$ Few prior studies have evaluated relationships of facilitator experience in PBL on student outcomes, which was the purpose of this study. In addition, the current study utilized both MEQ and MCQ assessments to evaluate different aspects of student acquisition and application of knowledge.

\section{METHODS}

Subjects were 378 students in the Master of Physician Assistant Studies (MPAS) classes of 2014 (N=78), 2015 (N=77), 2016 $(\mathrm{N}=77), 2017(\mathrm{~N}=78)$, and $2018(\mathrm{~N}=71)$ enrolled in the main clinical medicine courses of the curriculum-Essentials for the Physician Assistant I and II, which take place over the two didactic semesters of the program. These numbers do not include four students who repeated portions of the clinical medicine course for personal or academic reasons. Because this study focused on facilitator factors rather than individual factors, neither psychosocial nor demographic data of students were extracted.

The evaluative measures used in this study are scores from six multiple choice question (MCQ) examinations and six patient management assessments (PMA), one each from six 5-week units arranged by organ system. The MCQ examinations are all 100 questions in length; the score is the percentage of correct answers (high score is "better" than low score). The PMA is a modified-essay question-type examination which consists of three clinical problems. Each problem is further broken down into pages; as students progress through the pages, they are given additional information regarding the patient scenario and then required to critically and clinically evaluate the information presented and answer associated questions. Most of the pages require higher level thinking (ie, interpret lab data then diagnose and design a treatment plan), though some pages do ask for students to recall factual information (ie, describe what different lab tests measure). The grade is a compilation of total errors made on the examination, such that a higher score indicates more errors made (high score is "worse" than low score). All evaluative measures used in this study have been part of the didactic phase of the PA curriculum since its inception in 1996.

Each 5-week unit is taught by a different facilitator, either full-time or adjunct faculty. Students have different facilitators for each of the six units in the first (didactic) year of the curriculum. Faculty are either graduates of the program in this study, which uses PBL for the majority of the didactic curriculum, or graduates of PA programs using lecture as the primary pedagogical method. Each facilitator completed a 2-day training in the Barrows (Southern Illinois University) model of PBL. All but 2 of the 28 facilitators were trained by the same person, and one of the remaining two facilitators trained the other 26 facilitators. Additionally, facilitators undergo observation by their peers (every two years on average) to receive feedback on their technique as a way of promoting consistent delivery of the curriculum. Facilitators also attend once to twice weekly meetings to talk about the PBL cases and how they are progressing, again to prevent behavioral drift and promote consistency between facilitators.

Students and instructors were de-identified prior to statistical analysis of the data. No demographic data were collected to avoid identifying subjects. Research was approved by the University Internal Review Board. The didactic curriculum outcome data (MCQ and PMA scores) were entered into an Excel Spreadsheet. Also included in the spreadsheet was the total number of units each facilitator had taught in this course prior to the unit in which the examinations took place. Thus, if it was a facilitator's first time teaching in this course (ie, no prior experience), that facilitator would have zero (0) units of experience. A facilitator who had previously taught 10 units of PBL would have 10 units of experience. This number increased with each subsequent unit taught. "Facilitator experience" was on a continuum from 0 to 127 units previously facilitated. The facilitator was coded as either: 1) fulltime faculty or adjunct faculty and 2) as a graduate of the PA program in this study or of another PA program. A total of 28 facilitators led PBL groups during the five years of the study.

Data were analyzed using correlations and ANOVAs with SPSS. Four students were excluded who repeated portions of the didactic curriculum, and for analyses specifically involving facilitator experience, we excluded students who had more than one facilitator for the same unit (see tables for Ns related to this exclusion criterion).

\section{RESULTS}

In order to determine correlations between PMA and MCQ scores, Pearson product-moment correlations were computed for each unit, comparing PMA scores for each unit with MCQ scores for that unit (MCQ scores for unit 1 with PMA scores for unit 1 ,

(c) The Internet Journal of Allied Health Sciences and Practice, 2018 
MCQ scores for unit 2 with PMA scores for unit 2, etc.). We utilized only those participants who had both MCQ and PMA scores for all six units, eliminating participants listwise with any missing data. This resulted in a total of 354 participants. In order to correct for the number of computations made and maintain alpha at a maximum of .05, we utilized .001 as the level of significance throughout this study. Correlations between MCQ and PMA scores were all statistically significant and in the expected negative direction (ie, as PMA scores increased, MCQ scores decreased; see Table 1).

Utilizing only participants who had scores for both tests for all six units may have attenuated the correlations due to eliminating participants with low scores on the first few units. Thus, we also computed correlations pairwise (ie, computing correlations among participants with both scores at each respective unit). Correlations between MCQ and PMA scores were, as expected, larger than correlations of the restricted sample for all but units 5 and 6 , which contained the same number of participants as previous correlations for those units because ultimately all those students graduated (see Table 1), thereby revealing the expected attenuation effect. Given this and the importance of utilizing the full range of data (ie, including data from relatively weak students as well as those who successfully completed the program), we used pairwise deletion of data for all future analyses.

\begin{tabular}{|l|c|c|c|c|c|c|}
\hline \multicolumn{7}{|c|}{ Table 1. Correlations Between PMA and MCQ Scores for All Six Units } \\
\hline & $\begin{array}{c}\text { Unit 1 } \\
\mathrm{r}(\mathrm{p})\end{array}$ & $\begin{array}{c}\text { Unit 2 } \\
\mathrm{r}(\mathrm{p})\end{array}$ & $\begin{array}{c}\text { Unit 3 } \\
\mathrm{r}(\mathrm{p})\end{array}$ & $\begin{array}{c}\text { Unit } \\
\mathrm{r}(\mathrm{p})\end{array}$ & $\begin{array}{c}\text { Unit } 5 \\
\mathrm{r}(\mathrm{p})\end{array}$ & $\begin{array}{c}\text { Unit } 6 \\
\mathrm{r}(\mathrm{p})\end{array}$ \\
\hline $\begin{array}{l}\text { Participants } \\
\text { with } \\
\text { complete } \\
\text { data only } \\
(\mathrm{n}=354)\end{array}$ & $-.415(.000)$ & $-.529(.000)$ & $-.361(.000)$ & $-.171(.001)$ & $-.359(.000)$ & $-.360(.000)$ \\
\hline $\begin{array}{l}\text { All } \\
\text { participants }\end{array}$ & $\begin{array}{c}-.504(.000) \\
\mathrm{n}=377\end{array}$ & $\begin{array}{c}-.568(.000) \\
\mathrm{n}=370\end{array}$ & $\begin{array}{c}-.381(.000) \\
\mathrm{n}=362\end{array}$ & $\begin{array}{c}-.194(.000) \\
\mathrm{n}=355\end{array}$ & $\begin{array}{c}-.359(.000) \\
\mathrm{n}=354\end{array}$ & $\begin{array}{c}-.360(.000) \\
\mathrm{n}=354\end{array}$ \\
\hline
\end{tabular}

In order to determine relationships between facilitator experience and scores on the PMA and MCQ tests, Pearson product moment correlations were computed using the .001 level of significance as our criterion level of significance and found no statistically significant correlations (see Table 2). We also wanted to determine if there was any difference in PMA or MCQ scores based on whether (a) faculty were full-time or adjuncts and (b) graduated from the program (and thereby having personal experience as a learner in the PBL model) or from another program. Univariate analysis of variance tests with variables of interest (full-time versus adjunct and graduated from the program versus not) as independent variables and MCQ and PMA scores as dependent variables were computed. Analyses revealed no statistically significant differences with regard to PMA or MCQ scores (see Tables 3, 4, 5, and 6).

Table 2. Correlations (Significance) of Faculty Experience With MCQ and PMA Scores by Unit

\begin{tabular}{|l|c|c|c|c|c|c|}
\hline & Unit 1 & Unit 2 & Unit 3 & Unit 4 & Unit 5 & Unit 6 \\
& $r(p)$ & $r(p)$ & $r(p)$ & $r(p)$ & $r(p)$ & $r(p)$ \\
\hline MCQ & $.019(.716)$ & $-.045(.389)$ & $-.056(.289)$ & $-.029(.586)$ & $-.126(.020)$ & $.010(.850)$ \\
& $n=377$ & $n=373$ & $n=363$ & $n=355$ & $n=339$ & $n=338$ \\
\hline PMA & $-.072(.164)$ & $-.018(.734)$ & $-.028(.593)$ & $.107(.044)$ & $-.082(.130)$ & $.092(.091)$ \\
& $n=377$ & $n=372$ & $n=361$ & $n=355$ & $n=338$ & $n=338$ \\
\hline
\end{tabular}

$r-$ Pearson product-moment correlation

$p$ - statistical significance level 
Table 3. Univariate Analyses of Variance (ANOVA) Comparing Full-Time Versus Adjunct Faculty Status on MCQ Scores

\begin{tabular}{|c|c|c|c|c|c|}
\hline & & Mean & Standard Deviation & $\mathrm{F}$ & $p$ \\
\hline \multirow[b]{2}{*}{ MCQ1 } & $\begin{array}{l}\text { Adjunct faculty } \\
n=208\end{array}$ & 70.61 & 8.74 & \multirow[b]{2}{*}{1.95} & \multirow[b]{2}{*}{.164} \\
\hline & $\begin{array}{l}\text { Full-time faculty } \\
n=169\end{array}$ & 71.83 & 8.10 & & \\
\hline \multirow[b]{2}{*}{ MCQ2 } & $\begin{array}{l}\text { Adjunct faculty } \\
\mathrm{n}=197\end{array}$ & 72.70 & 8.34 & \multirow[b]{2}{*}{0.36} & \multirow[b]{2}{*}{.547} \\
\hline & $\begin{array}{l}\text { Full-time faculty } \\
\mathrm{n}=176\end{array}$ & 72.18 & 8.30 & & \\
\hline \multirow[b]{2}{*}{ MCQ3 } & $\begin{array}{l}\text { Adjunct faculty } \\
\mathrm{n}=212\end{array}$ & 72.39 & 9.16 & \multirow[b]{2}{*}{0.57} & \multirow[b]{2}{*}{.451} \\
\hline & $\begin{array}{l}\text { Full-time faculty } \\
n=152\end{array}$ & 71.67 & 8.61 & & \\
\hline \multirow[b]{2}{*}{ MCQ4 } & $\begin{array}{l}\text { Adjunct faculty } \\
\mathrm{n}=234\end{array}$ & 72.43 & 8.41 & \multirow[b]{2}{*}{4.23} & \multirow[b]{2}{*}{.040} \\
\hline & $\begin{array}{l}\text { Full-time faculty } \\
n=121\end{array}$ & 70.53 & 7.94 & & \\
\hline \multirow[b]{2}{*}{ MCQ5 } & $\begin{array}{l}\text { Adjunct faculty } \\
n=218\end{array}$ & 76.03 & 7.38 & \multirow[b]{2}{*}{0.06} & \multirow[b]{2}{*}{.805} \\
\hline & $\begin{array}{l}\text { Full-time faculty } \\
n=121\end{array}$ & 76.24 & 7.51 & & \\
\hline \multirow[b]{2}{*}{ MCQ6 } & $\begin{array}{l}\text { Adjunct faculty } \\
n=223\end{array}$ & 76.27 & 8.27 & \multirow[b]{2}{*}{1.06} & \multirow[b]{2}{*}{.303} \\
\hline & $\begin{array}{l}\text { Full-time faculty } \\
n=114\end{array}$ & 75.31 & 7.73 & & \\
\hline
\end{tabular}

$\mathrm{n}$ represents the number of students taught by full-time versus adjunct faculty.

Table 4. Univariate Analyses of Variance (ANOVA) Comparing Full-Time Versus Adjunct Faculty Status on PMA Scores

\begin{tabular}{|c|c|c|c|c|c|}
\hline 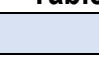 & 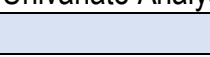 & Mean & Standard Deviation & $\mathrm{F}$ & $p$ \\
\hline \multirow[b]{2}{*}{ PMA1 } & $\begin{array}{l}\text { Adjunct faculty } \\
n=208\end{array}$ & 50.05 & 14.85 & \multirow[b]{2}{*}{0.56} & \multirow[b]{2}{*}{.455} \\
\hline & $\begin{array}{l}\text { Full-time faculty } \\
n=169\end{array}$ & 48.85 & 16.46 & & \\
\hline \multirow[b]{2}{*}{ PMA2 } & $\begin{array}{l}\text { Adjunct faculty } \\
n=199\end{array}$ & 49.85 & 11.59 & \multirow[b]{2}{*}{1.67} & \multirow[b]{2}{*}{.197} \\
\hline & $\begin{array}{l}\text { Full-time faculty } \\
n=173\end{array}$ & 48.42 & 9.49 & & \\
\hline \multirow[b]{2}{*}{ PMA3 } & $\begin{array}{l}\text { Adjunct faculty } \\
n=211\end{array}$ & 47.56 & 15.15 & \multirow[b]{2}{*}{0.03} & \multirow[b]{2}{*}{.855} \\
\hline & $\begin{array}{l}\text { Full-time faculty } \\
n=151\end{array}$ & 47.29 & 12.22 & & \\
\hline \multirow[b]{2}{*}{ PMA4 } & $\begin{array}{l}\text { Adjunct faculty } \\
n=234\end{array}$ & 44.05 & 12.35 & \multirow[b]{2}{*}{0.03} & \multirow[b]{2}{*}{.872} \\
\hline & $\begin{array}{l}\text { Full-time faculty } \\
n=121\end{array}$ & 44.29 & 14.58 & & \\
\hline \multirow[b]{2}{*}{ PMA5 } & $\begin{array}{l}\text { Adjunct faculty } \\
n=217\end{array}$ & 43.76 & 9.52 & \multirow[b]{2}{*}{3.53} & \multirow[b]{2}{*}{.061} \\
\hline & $\begin{array}{l}\text { Full-time faculty } \\
n=121\end{array}$ & 41.75 & 9.24 & & \\
\hline \multirow[b]{2}{*}{ PMA6 } & $\begin{array}{l}\text { Adjunct faculty } \\
n=223\end{array}$ & 44.00 & 10.81 & \multirow[b]{2}{*}{3.36} & \multirow[b]{2}{*}{.068} \\
\hline & $\begin{array}{l}\text { Full-time faculty } \\
n=114\end{array}$ & 46.27 & 10.61 & & \\
\hline
\end{tabular}

$\mathrm{n}$ represents the number of students taught by full-time versus adjunct faculty. 
Table 5. Univariate Analyses of Variance (ANOVA) Comparing Faculty Who Were Graduates of the Program Versus Faculty Who Were Not Graduates of the Program on MCQ Scores

\begin{tabular}{|c|c|c|c|c|c|}
\hline & & Mean & Standard Deviation & $\mathrm{F}$ & $p$ \\
\hline \multirow[b]{2}{*}{ MCQ1 } & $\begin{array}{l}\text { Not a program graduate } \\
n=150\end{array}$ & 70.63 & 8.41 & \multirow[b]{2}{*}{0.94} & \multirow[b]{2}{*}{.333} \\
\hline & $\begin{array}{l}\text { Program graduate } \\
n=227\end{array}$ & 71.50 & 8.51 & & \\
\hline \multirow[b]{2}{*}{ MCQ2 } & $\begin{array}{l}\text { Not a program graduate } \\
n=185\end{array}$ & 71.67 & 8.60 & \multirow[b]{2}{*}{3.27} & \multirow[b]{2}{*}{.072} \\
\hline & $\begin{array}{l}\text { Program graduate } \\
n=188\end{array}$ & 73.23 & 7.97 & & \\
\hline \multirow[b]{2}{*}{ MCQ3 } & $\begin{array}{l}\text { Not a program graduate } \\
n=142\end{array}$ & 72.12 & 8.40 & \multirow[b]{2}{*}{0.00} & \multirow[b]{2}{*}{.957} \\
\hline & $\begin{array}{l}\text { Program graduate } \\
n=222\end{array}$ & 72.07 & 9.27 & & \\
\hline \multirow[b]{2}{*}{ MCQ4 } & $\begin{array}{l}\text { Not a program graduate } \\
\mathrm{n}=141\end{array}$ & 72.67 & 7.37 & \multirow[b]{2}{*}{2.72} & \multirow[b]{2}{*}{.100} \\
\hline & $\begin{array}{l}\text { Program graduate } \\
n=214\end{array}$ & 71.19 & 8.81 & & \\
\hline \multirow[b]{2}{*}{ MCQ5 } & $\begin{array}{l}\text { Not a program graduate } \\
n=143\end{array}$ & 75.69 & 7.57 & \multirow[b]{2}{*}{0.77} & \multirow[b]{2}{*}{.381} \\
\hline & $\begin{array}{l}\text { Program graduate } \\
n=196\end{array}$ & 76.41 & 7.30 & & \\
\hline \multirow[b]{2}{*}{ MCQ6 } & $\begin{array}{l}\text { Not a program graduate } \\
n=127\end{array}$ & 76.01 & 7.62 & \multirow[b]{2}{*}{0.01} & \multirow[b]{2}{*}{.909} \\
\hline & $\begin{array}{l}\text { Program graduate } \\
n=210\end{array}$ & 75.90 & 8.38 & & \\
\hline
\end{tabular}

$\mathrm{n}$ represents the number of students taught by faculty who graduated from the PA program at the site of this study versus faculty who graduated from PA programs at other institutions.

Table 6. Univariate Analyses of Variance (ANOVA) Comparing Faculty Who Were Graduates of the Program Versus Faculty Who Were Not Graduates of the Program on PMA Scores

\begin{tabular}{|c|c|c|c|c|c|}
\hline & & Mean & Standard Deviation & $\mathrm{F}$ & $p$ \\
\hline \multirow[b]{2}{*}{ PMA1 } & $\begin{array}{l}\text { Not a program graduate } \\
n=150\end{array}$ & 49.92 & 15.77 & \multirow[b]{2}{*}{0.17} & \multirow[b]{2}{*}{.680} \\
\hline & $\begin{array}{l}\text { Program graduate } \\
\mathrm{n}=227\end{array}$ & 49.24 & 15.49 & & \\
\hline \multirow[b]{2}{*}{ PMA2 } & $\begin{array}{l}\text { Not a program graduate } \\
n=184\end{array}$ & 49.88 & 10.76 & \multirow[b]{2}{*}{1.53} & \multirow[b]{2}{*}{.216} \\
\hline & $\begin{array}{l}\text { Program graduate } \\
n=188\end{array}$ & 48.51 & 10.57 & & \\
\hline \multirow[b]{2}{*}{ PMA3 } & $\begin{array}{l}\text { Not a program graduate } \\
n=142\end{array}$ & 45.91 & 11.99 & \multirow[b]{2}{*}{2.85} & \multirow[b]{2}{*}{.092} \\
\hline & $\begin{array}{l}\text { Program graduate } \\
n=220\end{array}$ & 48.45 & 15.08 & & \\
\hline \multirow[b]{2}{*}{ PMA4 } & $\begin{array}{l}\text { Not a program graduate } \\
n=141\end{array}$ & 45.26 & 13.28 & \multirow[b]{2}{*}{1.71} & \multirow[b]{2}{*}{.191} \\
\hline & $\begin{array}{l}\text { Program graduate } \\
n=214\end{array}$ & 43.39 & 13.01 & & \\
\hline
\end{tabular}




\begin{tabular}{|l|l|c|c|c|c|}
\hline & & Mean & Standard Deviation & F & \\
\hline \multirow{2}{*}{ PMA5 } & $\begin{array}{l}\text { Not a program graduate } \\
n=143\end{array}$ & 42.07 & 9.02 & \multirow{2}{*}{2.63} & .106 \\
\cline { 2 - 4 } & $\begin{array}{l}\text { Program graduate } \\
n=195\end{array}$ & 43.75 & 9.73 & & \\
\hline \multirow{2}{*}{ PMA6 } & $\begin{array}{l}\text { Not a program graduate } \\
n=127\end{array}$ & 45.32 & 10.90 & \multirow{2}{*}{0.53} & .466 \\
\cline { 2 - 4 } & $\begin{array}{l}\text { Program graduate } \\
n=210\end{array}$ & 44.44 & 10.72 & \\
\hline
\end{tabular}

(n) represents the number of students taught by faculty who graduated from the PA program at the site of this study versus faculty who graduated from PA programs at other institutions.

\section{DISCUSSION}

This study demonstrates that experience alone facilitating PBL does not correlate with outcomes on evaluative measures. Because of this, other factors must affect student outcomes. While multiple studies have examined facilitator content expertise related to student outcomes in PBL, few studies specifically looked at experience facilitating PBL. ${ }^{13}$ In addition, few studies have looked at lecture-based faculty experience related to student outcomes. Hawkins et a $\left.\right|^{14}$ found a relationship between facilitator experience and evaluative measures; when, however, two facilitators with significantly more experience than the rest of the faculty in the study were removed from the data analysis, no significant differences in student outcomes were noted. The current study was able to expand on that research in several ways. First, rather than dividing faculty into only two groups (experienced and novice), each facilitator's experience was calculated as a total of 5-week units of facilitation, allowing for highly specific calculations of experience for each facilitator and the ability to account for the growth of experience with each additional unit facilitated. Second, instead of using only one year of data, the current study used five years of data and a large subject pool compared to the prior study by Hawkins et al. ${ }^{14}$ The range of experience from zero previously facilitated 5-week units to 127 previously facilitated units provides a variety of levels with which to compare outcomes. This expansive dataset allows for generalization of the results.

Since each of the facilitators in the current study undergoes rigorous training, observation, and participation in weekly meetings, these factors may outweigh the effects of facilitator experience. The literature, in general, supports the notion of initial and ongoing faculty development of facilitation skills. ${ }^{13}$ Despite this, some studies have utilized facilitators with minimal training, which may have inadvertently negatively affected student outcomes. ${ }^{13}$ Programs using PBL as a pedagogical method would likely benefit from consistent training and observation of facilitators, as well as frequent facilitator meetings to avoid "drift" in technique. As this is the procedure for the program where the study took place, further study would need to be done to determine if the training processes contributed to equalizing student outcomes for facilitators who graduated from the program in this study and facilitators who graduated from programs whose primary delivery of information was via lectures. All facilitators in the current study underwent the same training and observation protocol. Further study could determine whether faculty training and development contributes to consistency among facilitators and therefore reduces individual facilitator effect on student outcomes.

Similarly, there was no correlation between full-time versus adjunct status of facilitators with student evaluative outcomes. Given the faculty-intense nature of PBL, this should be of help to PA programs in selecting and training facilitators. Trained, supervised adjuncts may provide a helpful addition to full-time faculty, and the variety of experiences adjuncts bring can enhance the PBL atmosphere. A well-trained and well-supervised faculty can provide effective PA education regardless of experience or full-time versus adjunct status.

Although correlated, the results from this study indicate that MCQ tests and PMA exams are evaluating different constructs. Hift asserts that open-ended evaluations are not superior to the more common MCQ examinations in terms of evaluating higher levels of cognitive thinking when such MCQ items are appropriately written to test higher levels of cognitive thinking. ${ }^{16}$ If, however, the different constructs are valuable to clinical practice, then they are worth evaluating. Because MCQs promote cueing by providing the correct answer and the PMAs do not, PMAs may actually resemble and be more representative of the thought process associated with clinical practice, where answers are not provided beforehand, more than MCQs do. Results of the current study indicate that the MCQ and PMA evaluations appear to measure different constructs and therefore may be important in the complete evaluation of health care students. The low to moderate correlations between MCQ and PMA scores indicate that they are indeed measuring different aspects of their knowledge application. Based on these results, other application-based programs might consider implementation of MEQ-type evaluations. The program of the current study is a

(C) The Internet Journal of Allied Health Sciences and Practice, 2018 
hybrid of PBL and lecture-based education, where 18 of the 45 credits in the preclinical curriculum are taught entirely through PBL. Therefore, results of this study may not be generalizable to programs utilizing more or less PBL in their didactic curriculum. Finally, another possibility is that individual factors such as connectedness to the facilitator and/or PBL group members, selfmotivation, or self-efficacy may have more of an effect on outcomes than facilitator experience. ${ }^{18}$

Although no single factor or combination of factors has been shown to predict academic success in a PA program, characteristics such as individual intellectual ability, emotional stability, motivation, self-efficacy, and perseverance should be examined as possible predictors of outcomes. In fact, there are few studies that have definitively identified predictors of success in PA programs at all. Research into predictors of academic success at the undergraduate level seem to have centered on three general areas: (a) factors related to general academic culture of the institution or program, (b) factors related to the academic program itself, and (c) factors related to personal characteristics. An example of a general academic institutional factor shown to be predictive of academic achievement was school climate, specifically identification with the school. ${ }^{19}$ The role of general school/social environmental factors appears to vary depending upon institutional type and program, however. For example, one recent study showed that predictors of academic success among students attending a university-based curricular program differed significantly from those attending a community college, with environmental factors more of a predictor for community college students than for those attending a university-based curriculum. ${ }^{20}$ It seems likely that the graduate experience of a PA program will have differing predictors than that of either undergraduate experience, and research into this area might prove fruitful in understanding factors affecting graduate students.

Some research has shown that one of the program-specific factors that predicts academic success is student-instructor rapport.21 This would seem to be an especially important factor in programs that utilize problem-based learning approaches, where facilitators are interacting with small groups, necessitating close interactions. In fact, the differences between lecturebased pedagogy and PBL pedagogy is so significant that future research does need to evaluate the importance of facilitatorstudent relationship/rapport in predicting student success. ${ }^{22}$ One recent study did find data that highlights the importance of rapport building as integral to navigating the complex social interaction demands of problem-based learning groups. ${ }^{23}$

Another important personal factor is locus of control, specifically perceptions of academic control. Undergraduate students who report high levels of perceived academic control also have high levels of academic success and enjoyment and low levels of intentions to drop out of school. ${ }^{24}$ The student-centered approach of PBL may be of significant benefit to retention of students in PBL-based PA programs. Conversely, the high demands and expectations for independent work may challenge students who enter programs with low levels of perceived academic control. Future research needs to evaluate this. Other research has shown that personal factors related to study skills, self-regulation/self-control, and motivation to succeed are among the most important factors, but these studies also utilize undergraduate participants. One study that did utilize physician assistant students found that student self-efficacy predicted their clinical performance. ${ }^{18}$ This study, however, needs to be replicated with students in a PBL-based curriculum to see if these results generalize to the PBL format.

Areas for future study include examining individual students to investigate whether individual ability accounts for the variance between students on evaluative measures. If individual student outcomes remain relatively stable across facilitators, then studies of factors such as self-efficacy, locus of control, test-taking skills, test anxiety, and intellectual ability need to be pursued. Similarly, individual facilitators should be examined to determine whether there are "outliers" whose students do score differently on evaluative measures, even if as a whole there is no correlation between facilitator experience and outcomes. Perhaps certain facilitators "hint" (whether consciously or unconsciously) about content appearing on examinations, or there might be individuals whose students score particularly well or particularly badly as new facilitators. Conversely, some facilitators might be exhibiting behaviors correlated with higher evaluative scores, such that emulation of their techniques could improve everyone's performance. If such outliers exist, they should be observed by independent scorers to look for "drift" from the facilitation process or potential additions to best practices. Another area for future study would be correlation of MCQ and PMA evaluations with clinical evaluations in the rotation/clerkship phase of PA education as well as practice outcomes.

\section{REFERENCES:}

1. Preeti $B$, Ashish A, Shriram G. Problem Based Learning (PBL)- An effective approach to improve learning outcomes in medical teaching. J Clin Diagn Res. Dec 2013;7(12):2896-2897. [PMID: 24551668]

2. Loyens SMM, Jones SH, Mikkers J, van Gog T. Problem-based learning as a facilitator of cognitive change. Learning Instruction. 2015;38:34-42. http://dx.doi.org/10.1016/j.learninstruc.2015.03.002

(c) The Internet Journal of Allied Health Sciences and Practice, 2018 
3. Matthes J, Marxen B, Linke RM, Antepohl W, Coburger S, et al. The influence of tutor qualification on the process and outcome of learning in a problem-based course of basic medical pharmacology. Naunyn Schmiedebergs Arch Pharmacol. 2002;366:58-63. [PMID: 12107634]

4. Prosser M, Sze D. Problem-based learning: Student learning experiences and outcomes. Clin Linguistic Phon. 2014;28(12):112-123. [PMID: 23944271]

5. Van Berkel $\mathrm{H}$, Dolmans $\mathrm{D}$. The influence of tutoring competencies on problems, group functioning and student achievement in problem-based learning. Med Educ. 2006;40:730-736. [PMID: 16869917]

6. Yew EHJ, Goh K. Problem-based learning: An overview of its process and impact on learning. Hlth Prof Educ 2. 2016;7579. https://doi.org/10.1016/i.hpe.2016.01.004

7. Williams JC, Paltridge DJ. What we think we know about the tutor in problem-based learning. Hlth Prof Educ 3. 2017;26-31. https://doi.org/10.1016/i.hpe.2016.05.001

8. Ahmed IAM, Elseed MAM, El-Sheikh MA. Expert and non-expert tutors: role in problem-based learning. Med Sci Educator. 2007;17(1):9-13.

9. Bochner DB, Badovinac RL, Howell TH, Karimbux NY. Tutoring in a problem-based curriculum: Expert versus nonexpert. J Dent Educ. 2002;66(11):1246-1251. [PMID: 12484676]

10. Sakai DH, D'Eon M, Trinder K, Kasuya RT. The effect of senior medical student tutors compared to faculty tutors on examination scores of first- and second-year medical students in two problem-based learning courses. Interdisc J ProblemBased Learning. 2016;10(1). https://doi.org/10.7771/1541-5015.1533

11. Park SE, Susarla SM, Cox CK, Da Silva J, Howell TH. Do tutor expertise and experience influence student performance in a problem-based curriculum? J Dent Educ. 2007;71(6):819-824. [PMID: 17554099]

12. Gingerich A, Mader H, Payne GW. Problem-based learning tutors within medical curricula: An interprofessional analysis. $J$ Interprof Care. 2012;26:69-70. [PMID: 22233372]

13. Leary $\mathrm{H}$, Walker $\mathrm{A}$, Shleton $\mathrm{BE}$, Fitt MH. Exploring the relationships between tutor background, tutor training, and student learning: A problem-based learning meta-analysis. Interdisc J Problem-Based Learning. 2013;7(1):40-66. http://dx.doi.org/10.7771/1541-5015.1331

14. Hawkins S, Hertweck M, Laird J, Sekhon L, Kortyna D. The effect of experienced vs. novice problem-based learning facilitators on student outcomes. J Physician Assistant Educ. 2007;18(4):43-49.

15. Epstein RM. Assessment in medical education. N Engl J Med. 2007;356:387-396. [PMID: 17251535]

16. Hift RJ. Should essays and other "open-ended"-type questions retain a place in written summative assessment in clinical medicine? BMC Med Educ. 2014;14:249. [PMID: 25431359]

17. Palmer EJ, Devitt PG. Assessment of higher order cognitive skills in undergraduate education: modified essay or multiple choice questions? Research paper. BMC Med Educ. 2007;7:49. [PMID: 18045500]

18. Opacic DA. The relationship between self-efficacy and student physician assistant clinical performance. $J$ Allied Health. 2003;32:158-166. [PMID: 14526897]

19. Reynolds KJ, Lee E, Turner I, Bromhead D, Subasic E. How does school climate impact academic achievement? An examination of social identity processes. School Psych International. 2017;38:78-97. http://dx.doi.org/10.1177/0143034316682295

20. Heller ML, Cassady JC. Predicting community college and university student success: A test of the triadic reciprocal model for two populations. J College Student Retention: Research, Theory Practice. 2017;18:431-456. http://dx.doi.org/10.1177/1521025115611130

21. Lammers WJ, Gillaspy JA. Jr, Hancock F. Predicting academic success with early, middle, and late semester assessment of student-instructor rapport. Teaching Psych. 2017;44:145-149. http://dx.doi.org/10.1177/0098628317692618

22. Papinczak T. An exploration of perceptions of tutor evaluation in problem-based learning tutorials. Med Educ. 2010;44:892899. [PMID: 20716099]

23. Robinson L, Harris A, Burton R. Saving face: Managing rapport in a problem-based learning group. Active Learning Higher Educ. 2015;16:11-24. http://dx.doi.org/10.1177/1469787415573355

24. Respondek L, Seufert T, Stupnisky R, Nett UE. Perceived academic control and academic emotions predict undergraduate university student success: Examining effects on dropout intention and achievement. Front Psychol. 2017 Mar 7;8:243. [PMID: 28326043] 